\title{
The expression and underlying angiogenesis effect of DPC4 and VEGF on the progression of cervical carcinoma
}

\author{
YANNI A $^{1 *},{\text { YING } \mathrm{LI}^{2 *} \text { and SHUPING ZHAO }}^{3}$ \\ ${ }^{1}$ Department of Gynecology, Qingdao Women and Children Hospital; ${ }^{2}$ Department of Pathology, Qingdao Municipal Hospital \\ (Group); ${ }^{3}$ Department of Gynecology, The Affiliated Hospital of Qingdao University, Qingdao, Shandong 266000, P.R. China
}

Received January 7, 2016; Accepted June 29, 2017

DOI: $10.3892 / 01.2017 .7580$

\begin{abstract}
The present study aimed to investigate the expression and roles of deleted in pancreatic carcinoma locus 4 (DPC4) and vascular endothelial growth factor (VEGF) in the development of cervical carcinoma. A total of 115 patients aged between 25 and 60 years were involved, including 19 cervical inflammation, 35 cervical intraepithelial neoplasia (CIN), and 61 cervical squamous-cell carcinoma (CSCC). The protein expression rates of DPC4 and VEGF in all samples were detected using immunohistochemistry. The protein levels of DPC4 and VEGF in CSCC samples were measured using ELISA. Microvessel density (MVD) of each CSCC sample was measured according to the Winder method. Association analysis between DPC4, VEGF and thrombospondin-1 (TSP-1) was conducted using Spearman's correlations. The negative expression rate of DPC4 [DPC4 (-)] and positive expression rate of VEGF [VEGF (+)] of the CSCC group were significantly higher compared with that in the cervical inflammation and CIN groups $(\mathrm{P}<0.05)$. In the CSCC group, the protein level of DPC4 decreased, while the VEGF level increased significantly compared with the healthy control group $(\mathrm{P}<0.05)$. The MVD in the DPC4 (-), VEGF (+) and TSP-1 (-) groups was significantly increased compared with that of the DPC4 (+), VEGF (-), and TSP-1 (+) groups $(\mathrm{P}<0.05)$. The expression of DPC4 was negatively associated with VEGF and TSP-1 $(\mathrm{P}<0.01)$. These results suggest that DPC4, VEGF and TSP-1 are involved in the carcinogenesis of cervical carcinoma by inducing angiogenesis. In addition, the loss of DPC4 induces angiogenesis through increasing VEGF. Thus, VEGF may be a target gene regulated by DPC4.
\end{abstract}

Correspondence to: Professor Shuping Zhao, Department of Gynecology, The Affiliated Hospital of Qingdao University, 16 Jiangsu Road, Qingdao, Shandong 266000, P.R. China

E-mail: shupzhzh@hotmail.com

*Contributed equally

Key words: deleted in pancreatic carcinoma locus 4, vascular endothelial growth factor, angiogenesis, cervical carcinoma

\section{Introduction}

Cervical carcinoma, also known as invasive carcinoma of cervix uteri, is a cancer arising from the cervix. It is ranked as the second most common type of cancer among women worldwide (1,2). Furthermore, cervical cancer was associated with 275,000 mortalities in $2008, \sim 88 \%$ of which occurred in developing countries (3). Therefore, the identification of molecular genes involved in the regulation of cervical carcinoma progression is warranted in order to develop novel therapeutic approaches for this cancer.

Several molecular genes have been reported to be associated with tumor progression, including deleted in pancreatic carcinoma locus 4 (DPC4/Smad4), vascular endothelial growth factor (VEGF) and thrombospondin-1 (TSP-1) (4). Loss of DPC4 contributes to the switch of transforming growth factor (TGF)- $\beta$ from a tumor-suppressive to a tumor-promoting pathway in cancer (5). Previous research demonstrated that a decrease in DPC4 mRNA expression is associated with lack of growth inhibition in human cervical carcinoma (6). VEGF and TSP-1 are regulatory molecules of angiogenesis (7), which is essential for the progression of cervical carcinoma (8). High expression of VEGF is associated with the degree of vascularization (9). In addition, the positive expression rate of VEGF in cervical carcinoma is higher compared with that in normal, inflammatory and cervical intraepithelial neoplasia (CIN) cervix (10). It has also been revealed that decreased TSP-1 expression correlates inversely with microvessel count in cervical carcinoma (11) and alters tumor growth by modulating angiogenesis (12). Furthermore, recent research suggests that VEGF and TSP-1 are key target genes for DPC4 (4), and the stable expression of DPC4 downregulates the expression of VEGF in cervical carcinoma (13). Although DPC4 and VEGF have been identified to be associated with cervical carcinoma, the involvement of the two with tumorigenesis, and the correlation between DPC4 and VEGF/TSP-1 in cervical carcinoma remain unclear.

In the present study, the expression levels of DPC4 and VEGF in cervical carcinoma were assessed in order to investigate the association between DPC4, VEGF, and clinicopathological characteristics of patients with cervical carcinoma. Furthermore, the microvessel density (MVD) of each cervical squamous-cell carcinoma (CSCC) sample was detected to investigate the effect of DPC4, VEGF and TSP-1 
on angiogenesis. In addition, the correlation between DPC4, VEGF and TSP-1 was investigated in order to elucidate the roles of DPC4 and VEGF in the progression of tumorigenesis, and their possible associations in carcinogenesis.

\section{Materials and methods}

Patients. The field study took place at the Second Clinical Hospital of Jilin University (Changchun, China) between August 2012 and August 2013. A total of 115 patients with invasive cervical carcinoma aged between 25 and 60 years (mean age, 46 years) were surgically treated to remove a tumor. All the patients were treated without radiotherapy, chemotherapy or other adjuvant therapy prior to surgery, and did not recently use drugs that affected the metabolism of prostaglandin and thromboxane. The 115 samples were identified by three pathologists independently, and the final diagnosis was confirmed when $\geq 2$ of the same results were obtained from the three pathologists. Lymph node metastasis and classification of tumors were regarded as the criteria. The samples included 19 cervical inflammation, 10 CIN I, 11 CIN II, 14 CIN III and 61 CSCC. Local pathologists were asked to provide complete clinical data of the patients with CSCC. The 61 CSCC samples, which were staged according to the International Federation of Gynecology and Obstetrics (14), were divided into stage I $(n=20)$, stage II $(n=25)$ and stage III $(n=16)$. Pathological grade assessment was also performed, and the CSCC samples were graded into G1 $(n=18), G 2(n=26)$ and G3 $(n=17)$ according to the proportion of differentiated cells (15). A total of 21 lymph node metastasis samples were involved in these CSCC samples. Finally, 12 fresh normal cervix tissue samples, which were acquired from individuals confirmed via necropsy to have succumbed to natural causes (and therefore unassociated with cervical complications) at the Second Clinical Hospital of Jilin University between August 2012 and August 2013, were used as normal controls.

Written informed consent was obtained from all the subjects or their parents. The present study was approved by the Ethics Committee of the Second Clinical Hospital of Jilin University and all study procedures were performed according to ethical standards.

Immunohistochemical analysis. Excess tissue and moisture were removed from the freshly obtained tissue samples. The samples were then dehydrated routinely and embedded in paraffin. Embedded tissues were sliced into 5- $\mu \mathrm{m}$ thick sections, deparaffinized in xylene followed by treatment with 95, 70 and 50\% ethanol, and rehydration with PBS (pH 7.4). Paraffin-embedded tissues were used for hematoxylin and eosin staining, and immunohistochemical analysis. Pathological diagnosis and pathological grade were established by two pathologists, respectively. Sections analyzed for protein expression (DPC4, VEGF and TSP-1) were microwaved for $5 \mathrm{~min}$ at $98^{\circ} \mathrm{C}$ in citrate buffer $(\mathrm{pH}$ 6.0) for antigen retrieval. Following these pretreatment procedures, all samples were incubated with a solution of $1 \%$ hydrogen peroxide in methanol for $15 \mathrm{~min}$ at room temperature to block endogenous peroxidase. Sections were washed three times with PBS (pH 7.5) and then incubated for $10 \mathrm{~min}$ at room temperature in $50 \mu \mathrm{l}$ normal non-immune goat serum (YeSen Biotechnology Co., Ltd.,
Shanghai, China). The rabbit anti-human primary monoclonal antibodies for DPC4, TSP-1 or VEGF (all at a dilution of 1:100; Shanghai Westang Bio-Tech Co., Ltd., Shanghai, China) were applied to the sections overnight at $4^{\circ} \mathrm{C}$. The next day the sections were rinsed three times in PBS and incubated for $10 \mathrm{~min}$ with the addition of goat anti-rabbit peroxidase-conjugated secondary antibody (1:50; Wuhan Boster Biological Technology, Ltd., Wuhan, China) for $1 \mathrm{~h}$ at room temperature. Following rinsing three times in PBS, the samples were incubated with $50 \mu \mathrm{l}$ streptavidin-peroxidase for another $10 \mathrm{~min}$ at room temperature. Then, the samples were washed with PBS and visualized with $100 \mu 1$ stable 3,3'-diaminobenzidine (Dako; Agilent Technologies, Inc., Santa Clara, CA, USA) for $10 \mathrm{~min}$ at room temperature. The reaction was stopped by washing with water and the sections were counterstained with Gill No. 3 hematoxylin solution (Sigma-Aldrich; Merck KGaA, Darmstadt, Germany). Following rinsing in PBS, the slides were dehydrated with 50, 70, 95\% and absolute ethanol, and mounted with neutral balsam. The slides were observed using an optical microscope (CH20BIMF2000; Olympus Corporation, Tokyo, Japan). Negative controls involved the same procedure; however, the primary antibody was replaced with PBS. As a positive control, a specimen of CSCC with strong expression of DPC4, VEGF or TSP-1 was used.

Protein expression was determined by two independent observers who semi-quantitatively assessed the staining intensity and the percentage of stained tumor cells. The staining intensity was rated as follows: 0 points, negative; 1 point, weak intensity; 2 points, moderate intensity; and 3 points, strong intensity. The percentage of positive cells was rated as follows: 0 points, $0 \%$ positive tumor cells; 1 point, $<30 \%$ positive cells; 2 points, $30-60 \%$ positive cells; and 3 points, $>60 \%$ positive cells. Points of staining intensity and percentage of positive cells were added, positive expression was regarded as $\geq 3$ points.

ELISA. The protein expression levels of DPC4 and VEGF in different pathological periods of CCSC were detected using an ELISA kit (Wuhan Boster Biological Technology, Ltd.) according to the manufacturer's protocol. The serum samples (100 $\mu \mathrm{l}$ ) were obtained by drawing peripheral blood and centrifuging for $10 \mathrm{~min}\left(1,760 \mathrm{x} \mathrm{g}\right.$ at $\left.4^{\circ} \mathrm{C}\right)$. The substrate used as the enzyme conjugate was tetramethylbenzidine. Optical density values were read at $450 \mathrm{~nm}$. Normal cervix samples were used as controls.

Quantification of MVD. The MVD of CSCC samples were determined according to the Winder method (16). Microvessels were highlighted by staining endothelial cells for Factor VIII (FVIII) with immunohistochemistry. The most vascularized areas (hot spots) with a high density of FVIII-positive cells were picked up using a low power field magnification (x40). The MVD was quantified using a x200 magnification high-power field (x10 ocular and x20 objective; field area; $0.25 \mathrm{~mm}^{2}$ ). All positively stained discrete cells or cell clusters with, or without visible lumina were counted as a microvessel. The branch structure of discrete cells, which did not connect with the primary structure, was also counted as a microvessel. However, vessels with a diameter greater than the sum of eight red blood cells, which had an evident muscular layer, were not 
counted. A total of three fields of view in each sample were counted and the average was represented as the MVD.

Statistical analysis. Statistical analysis was performed using SPSS 11.0 software (SPSS, Inc., Chicago, IL, USA). All data are expressed as the mean \pm standard deviation. Statistical significance of protein expression (DPC4, TSP-1 or VEGF) in the different groups was conducted using the $\chi^{2}$ test. In addition, paired t-tests were performed to estimate the statistical significance of MVD. Correlation analysis between DPC4 and VEGF/ TSP-1 was conducted by Spearman's correlations. $\mathrm{P}<0.05$ was considered to indicate a statistically significant difference.

\section{Results}

Protein expression rates of DPC4 and VEGF detected using immunohistochemistry. The negative expression rates of DPC4 in the normal control and chronic cervicitis groups were $0 \%$ (Fig. 1). The rates in the CIN I, CIN II and CIN III groups were 10,9 and $14.3 \%$ respectively, which were all significantly lower compared with that in the CSCC group (40.9\%; $\mathrm{P}<0.05$; Table I; Fig. 1). Regarding the expression of VEGF, the positive expression rates in the CIN I (10\%), CIN II (18.2\%) and CIN III (35.7\%) groups were significantly lower compared with that in the CSCC group (73.8\%; $\mathrm{P}<0.05)$. Furthermore, no VEGF expression was detected in the normal control and chronic cervicitis groups.

Association analysis between DPC4/VEGF and the clinical pathology of CSCC. As presented in Fig. 1A, DPC4 protein was located in the cytoplasm and karyon of normal cervical tissue, and irregularly distributed; however, the protein was located primarily in the cytoplasm of CSCC tissue (Fig. 1B) and was granulated. DPC4 protein staining exhibited claybank spot distribution. The negative expression rate of DPC4 in the stage I group was $20 \%$, significantly lower compared with that in the stage II group (56.3\%; P $<0.05$; Table II). However, no statistical difference was observed in pathological grade. In addition, the DPC4 protein expression was associated with lymph node metastasis (Table II), the negative rate in the lymph node metastasis group (71.4\%) was significantly higher compared with that of the lymph node metastasis-negative group (25.0\%; $\mathrm{P}<0.05$; Table II).

For VEGF, no expression was detected in normal cervical tissues (Fig. 1E), but the protein was located in the cytoplasm in CSCC (Fig. 1F) with granulated and dispersedly distributed claybank spot staining. The positive expression rate of VEGF in stage I was $60 \%$, which was decreased significantly compared with that in stage II $(84 \%$; $\mathrm{P}<0.05$; Table II). However, no statistical difference was observed in pathological grade. Furthermore, the positive rate of VEGF protein expression in the lymph node metastasis group (80.9\%) was significantly higher compared with that of the lymph node metastasis-negative group (47.5\%; $\mathrm{P}<0.05$; Table II).

Expression levels of DPC4 and VEGF in different clinical stages. As presented in Table III, the protein expression level of DPC4 in stage I, II and III were $39 \pm 2.01,34 \pm 2.2$, and $50 \pm 2.83$, respectively, which were significantly lower compared with
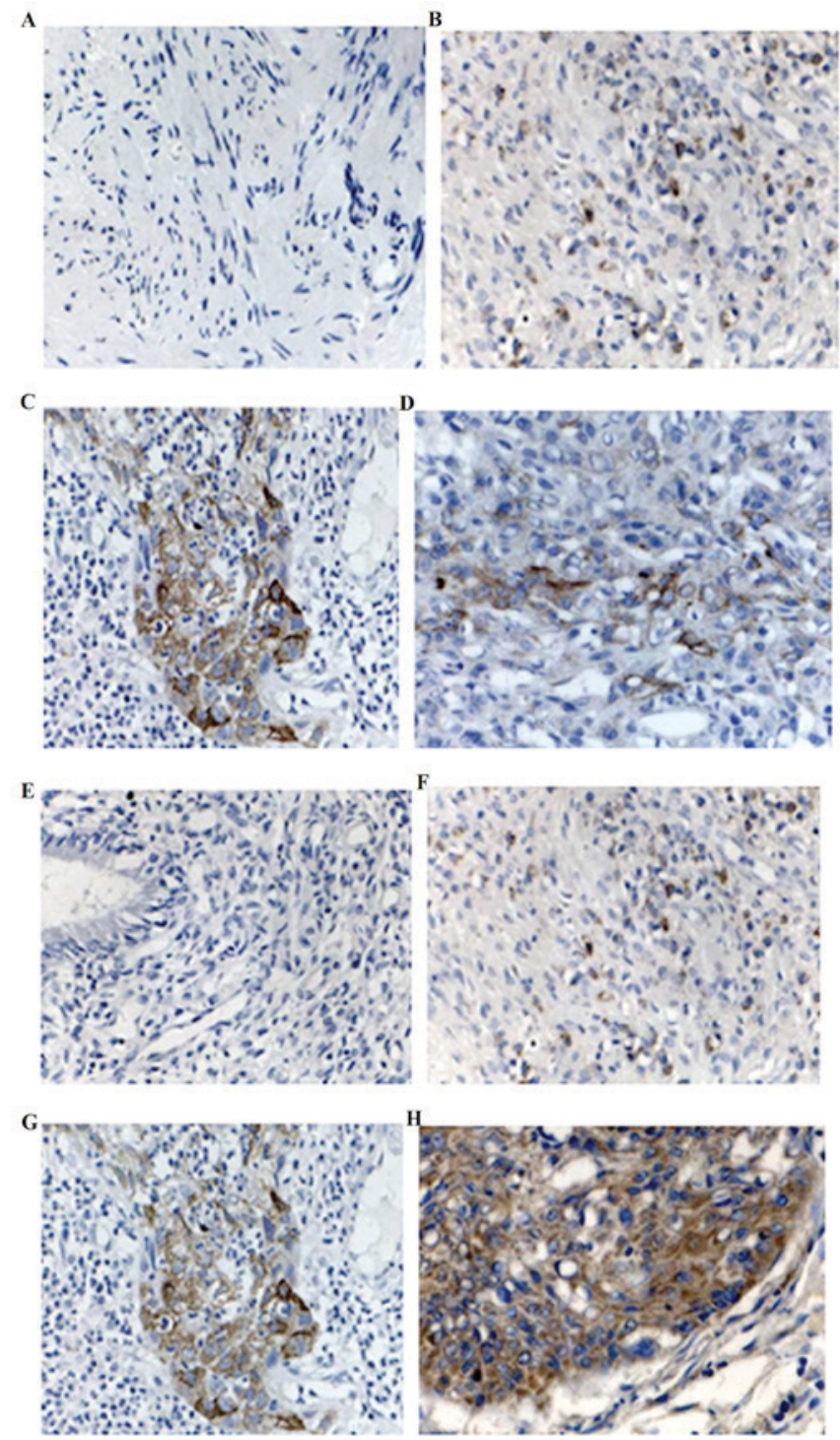

Figure 1. Immunohistochemistry results of DPC4 and VEGF expression levels. The expression of DPC4 in (A) normal cervix (magnification, x200), (B) stage I CSCC, (C) stage II CSCC and (D) stage III CSCC. The expression of VEGF in (E) normal cervix, (F) stage I CSCC, (G) stage II CSCC and (H) stage III CSCC. (B-H) Magnification, x400. CSCC, cervical squamous-cell carcinoma; DPC4, deleted in pancreatic carcinoma locus 4; VEGF, vascular endothelial growth factor.

that in the normal control group $(86 \pm 4.21 ; \mathrm{P}<0.05)$. However, for VEGF, the expression level in stage I $(90 \pm 4.40)$, stage II $(106 \pm 4.89)$ and stage III $(70 \pm 3.89)$ increased significantly compared with the normal control group $(26 \pm 1.83$; $\mathrm{P}<0.05)$.

Association between DPC4, VEGF, TSP-1 and tumor angiogenesis. As presented in Table IV, in CSCC samples, the MVD of the DPC4 (-) group $(8.38 \pm 3.15)$ was significantly higher compared with that of the DPC4 (+) group (11.28 \pm 3.55 ; $\mathrm{P}<0.05)$. The MVD of the VEGF (-) group (10.51 \pm 3.90$)$ was significantly lower compared with the VEGF (+) group (15.37 $\pm 4.59 ; \mathrm{P}<0.01)$. In addition, the MVD of the TSP-1 (-) group (15.37 \pm 3.10$)$ was significantly higher compared with the TSP-1 (+) group $(9.31 \pm 2.4 ; \mathrm{P}<0.01)$.

Statistical analysis demonstrated that the MVD in the DPC4 (-) TSP-1 (+) group (12.74 +3.59$)$ was significantly 
Table I. Expression of DPC4 and VEGF in cervical tissues of differential pathological types.

\begin{tabular}{|c|c|c|c|c|c|}
\hline \multirow[b]{2}{*}{ Group } & \multirow[b]{2}{*}{ No. of cases } & \multicolumn{2}{|c|}{ Negative expression of DPC4 } & \multicolumn{2}{|c|}{ Positive expression of VEGF } \\
\hline & & No. of cases & Negative rate, $\%$ & No. of cases & Positive rate, $\%$ \\
\hline Normal cervix & 12 & 0 & $0.0^{\mathrm{a}}$ & 0 & $0.0^{\mathrm{a}}$ \\
\hline Cervical inflammation & 19 & 0 & $0.0^{\mathrm{a}}$ & 0 & $0.0^{\mathrm{a}}$ \\
\hline CIN I & 10 & 1 & 10.0 & 1 & $10.0^{\mathrm{a}}$ \\
\hline CIN II & 11 & 1 & $9.0^{\mathrm{a}}$ & 2 & $18.2^{\mathrm{a}}$ \\
\hline CIN III & 14 & 2 & 14.3 & 5 & $35.7^{\mathrm{a}}$ \\
\hline $\operatorname{CCSC}$ & 61 & 21 & 40.9 & 45 & $73.8^{\mathrm{a}}$ \\
\hline
\end{tabular}

${ }^{a} \mathrm{P}<0.05$, compared with the CSCC. CSCC, cervical squamous-cell carcinoma; DPC4, deleted in pancreatic carcinoma locus 4; VEGF, vascular endothelial growth factor; CIN, cervical intraepithelial neoplasia.

Table II. Expression of DPC4 and VEGF in CSCC samples classified according to different clinicopathological factors.

\begin{tabular}{|c|c|c|c|c|c|}
\hline \multirow[b]{2}{*}{ Clinicopathological factor } & \multirow[b]{2}{*}{ No. of cases } & \multicolumn{2}{|c|}{ Negative expression of DPC4 } & \multicolumn{2}{|c|}{ Positive expression of VEGF } \\
\hline & & No. of cases & Negative rate, $\%$ & No. of cases & Positive rate, $\%$ \\
\hline \multicolumn{6}{|l|}{ Stage } \\
\hline $\mathrm{I}$ & 20 & 4 & 20.0 & 11 & $60.0^{\mathrm{b}}$ \\
\hline II & 25 & 7 & 48.0 & 22 & 84.0 \\
\hline III & 16 & 8 & $56.3^{\mathrm{a}}$ & 12 & 75.0 \\
\hline \multicolumn{6}{|l|}{ Grade } \\
\hline G1 & 18 & 5 & 22.2 & 13 & 72.2 \\
\hline $\mathrm{G} 2$ & 26 & 10 & 38.5 & 19 & 73.1 \\
\hline G3 & 17 & 10 & 64.7 & 13 & 76.5 \\
\hline \multicolumn{6}{|l|}{ Lymph node metastasis } \\
\hline $\mathrm{R}$ & 21 & 15 & $71.4^{\mathrm{c}}$ & 17 & $80.9^{c}$ \\
\hline $\mathrm{F}$ & 40 & 10 & 25.0 & 19 & 47.5 \\
\hline
\end{tabular}

${ }^{\text {aP }}<0.05$, compared with stage I; ${ }^{b} \mathrm{P}<0.05$, compared with stage II; ${ }^{\mathrm{c}} \mathrm{P}<0.05$, compared with $\mathrm{F}$. $\mathrm{R}$, CSCC samples with lymph node metastasis; F, CSCC without lymph node metastasis; CSCC, cervical squamous-cell carcinoma; DPC4, deleted in pancreatic carcinoma locus 4; VEGF, vascular endothelial growth factor.

Table III. Expression of DPC4 and VEGF in different stage of cervical squamous-cell carcinoma.

\begin{tabular}{lcccc}
\hline Expression & Normal cervix & Stage I & Stage II & Stage III \\
\hline DPC4 & $86 \pm 4.21$ & $39 \pm 2.01^{\mathrm{a}, \mathrm{b}}$ & $34 \pm 2.20^{\mathrm{a}}$ & $50 \pm 2.83^{\mathrm{a}}$ \\
VEGF & $26 \pm 1.83$ & $90 \pm 4.40^{\mathrm{a}, \mathrm{b}}$ & $106 \pm 4.89^{\mathrm{a}}$ & $70 \pm 3.89^{\mathrm{a}}$
\end{tabular}

${ }^{\mathrm{a}} \mathrm{P}<0.05$, compared with the normal cervix; ${ }^{\mathrm{b}} \mathrm{P}<0.05$, compared with the stage III. DPC4, deleted in pancreatic carcinoma locus 4; VEGF, vascular endothelial growth factor. All data are presented as the mean \pm standard deviation.

increased compared with the DPC4 (+) TSP-1 (-) group $(11.49 \pm 3.89)$, and significantly decreased compared with the DPC4 (+) TSP-1 (+) group $(19.38 \pm 3.35$; P<0.01). The MVD of DPC4 (-) VEGF (+) group (18.38 \pm 3.25$)$ was significantly higher compared with the DPC4 (+) VEGF (+) group (11.74 \pm 3.89$)$ and the DPC4 (+) VEGF (-) group $(10.39 \pm 3.89$; P<0.01).

A negative correlation was identified between the expression of DPC4 $(r=-0.762)$ and TSP-1 $(r=-0.578)$, and tumor angiogenesis (both $\mathrm{P}<0.01$; Table IV). However, a positive correlation between VEGF expression and tumor angiogenesis was reported $(r=0.478 ; \mathrm{P}<0.01$; Table IV).

Correlation between DPC4, VEGF and TSP-1. As presented in Table $\mathrm{V}$, the expression of DPC4 was identified to be negatively correlated with VEGF $(\mathrm{r}=-0.486 ; \mathrm{P}<0.01)$ and TSP-1 $(\mathrm{r}=-0.480 ; \mathrm{P}<0.01)$.

\section{Discussion}

Cervical carcinoma is a common type of gynecologic cancer caused by various factors. However, the mechanism underlying tumorigenesis remains to be elucidated. Loss of DPC4 and 
Table IV. Mean MVD of cervical squamous-cell carcinoma samples with positive/negative expression of DPC4, VEGF or TSP-1.

\begin{tabular}{lcc}
\hline Expression & No. of cases & MVD (mean \pm SD) \\
\hline DPC4 & 22 & $18.38 \pm 3.15$ \\
Negative & 39 & $11.28 \pm 3.55^{\mathrm{a}}$ \\
Positive & & \\
VEGF & 18 & $10.51 \pm 3.90$ \\
Negative & 43 & $15.37 \pm 4.59^{\mathrm{a}}$ \\
Positive & & \\
TSP-1 & 16 & $15.37 \pm 3.10$ \\
Negative & 45 & $9.31 \pm 2.40^{\mathrm{a}}$ \\
Positive & & \\
DPC4 and TSP-1 & 16 & $11.49 \pm 3.89^{\mathrm{b}}$ \\
DPC4 (+) TSP-1 (-) & 24 & $12.74 \pm 3.59$ \\
DPC4 (-) TSP-1 (+) & 21 & $19.34 \pm 3.55^{\mathrm{b}}$ \\
DPC4 (+) TSP-1 (+) & & \\
DPC4 and VEGF & 18 & $10.4 \pm 3.89^{\mathrm{c}}$ \\
DPC4 (+) VEGF (-) & 22 & $18.4 \pm 3.25$ \\
DPC4 (-) VEGF (+) & 21 & $11.74 \pm 3.89^{\mathrm{c}}$ \\
DPC4 (+) VEGF (+) & & \\
\hline
\end{tabular}

${ }^{\mathrm{a}} \mathrm{P}<0.001$, compared with the negative expression group; ${ }^{\mathrm{b}} \mathrm{P}<0.001$, compared with the DPC4 (-) TSP-1 (+) group; ${ }^{\mathrm{c}} \mathrm{P}<0.001$, compared with the DPC4 (-) VEGF (+) group; ${ }^{\mathrm{R}}$ values were only calculated for the correlations between DPC4, VEGF and TSP-1 with MVD. DPC4, deleted in pancreatic carcinoma locus 4; VEGF, vascular endothelial growth factor; MVD, microvessel density; TSP-1, thrombospondin- 1 ; SD, standard deviation.

Table V. Correlation between DPC4 and VEGF or TSP-1.

\begin{tabular}{|c|c|c|c|c|c|c|c|c|}
\hline \multirow[b]{2}{*}{ DPC4 } & \multicolumn{4}{|c|}{ VEGF } & \multicolumn{4}{|c|}{ TSP-1 } \\
\hline & + & - & $\mathrm{R}$ & P-value & + & - & $\mathrm{R}$ & P-value \\
\hline+ & 21 & 18 & -0.49 & $<0.01$ & 21 & 16 & 0.48 & $<0.01$ \\
\hline- & 22 & 0 & & & 24 & 0 & & \\
\hline
\end{tabular}

DPC4, deleted in pancreatic carcinoma locus 4; VEGF, vascular endothelial growth factor; TSP-1, thrombospondin-1.

overexpression of VEGF have been reported to be associated with cervical carcinoma carcinogenesis $(17,18)$. Thus, DPC4 and VEGF may be candidate molecules that contribute to the progression of cervical carcinoma. In the present study, it was demonstrated that the negative expression rate of DPC4 and positive expression rate of VEGF in the CSCC group were increased significantly compared with that in the normal, inflammatory, and CIN groups $(\mathrm{P}<0.05)$. In addition, DPC4 (-) and VEGF $(+)$ were associated with clinical stages, and lymph node metastasis. Furthermore, the expression levels of DPC4 and TSP-1 were identified to be negatively associated with angiogenesis. However, the expression of VEGF and angiogenesis were positively associated $(\mathrm{P}<0.01)$. The expression of DPC4 was negatively associated with VEGF and with TSP-1 $(\mathrm{P}<0.01)$.

DPC4 is a tumor suppressor gene frequently inactivated in various types of carcinoma, including cervical carcinoma (19-22).
Reduced or lost expression of DPC4 is frequently observed during cancer progression (13). In the present study, it was revealed that DPC4 was negatively expressed in CIN and CSCC tissues, and the negative expression rate increased gradually along with the progression of cervical carcinoma, corresponding with a study by Baldus et al (17). The results of the present study suggest that DPC4 is associated with the tumorigenesis of cervical carcinoma. Furthermore, previous evidence has reported that DPC4 alterations are associated with the specific loss of TGF- $\beta$-induced growth resulting in increased angiogenesis $(23,24)$. In the present study, the results demonstrated that the negative expression of DPC4 was associated with angiogenesis. In addition, it has been reported that DPC4 restoration can inhibit angiogenesis in different carcinoma types, including colon and pancreatic (25), lung (26) and pancreatic (4) cancer. These results indicate that the loss of DPC4 may contribute to cervical carcinoma progression via angiogenesis. 
VEGF is one of the most important angiogenesis factors in regulating angiogenesis. Its expression is associated with MVD (27) and a high expression level has been detected in numerous human tumor types, including lung (28), colon (29), and gastric (30) cancer. In the present study, a high positive expression rate and high level of VEGF were detected in cervical carcinoma. Furthermore, these results revealed that the expression of VEGF was positively associated with angiogenesis. As angiogenesis serves an important role in the progression of tumorigenesis, VEGF may participate in the tumorigenesis of cervical carcinoma by inducing angiogenesis.

As a potent inhibitor of neovascularization, TSP-1 also serves a key role in regulating angiogenesis. Reduced expression of TSP-1 can switch normal cells to an angiogenic phenotype, thus progressing cells towards malignancy (31). Overexpression of TSP-1 can reduce MVD and inhibit the growth of prostate cancer cells (32). The results of the present study reported that the MVD in the TSP-1 (-) group was significantly higher compared with that of the TSP-1 (+) group, indicating that angiogenesis of cervical carcinoma may be suppressed by TSP-1. Consistent with these results, a previous study demonstrated that microvessel counts are significantly higher when decreased TSP-1 mRNA expression is evident in cervical carcinoma (11). Therefore, TSP-1 may inhibit the angiogenesis of cervical carcinoma.

Due to the observations of decreased DPC4 expression and VEGF overexpression in the progression of angiogenesis, the correlation between DPC4, and VEGF was analyzed. The results demonstrated that they were associated. Correspondingly, it has been reported that carcinomas with high DPC4 expression are accompanied with low VEGF expression (26). Increased expression of DPC4 results in decreased expression levels of VEGF, shifting cells from an angiogenic to antiangiogenic phenotype in various cancer types, including pancreatic (4), gastrointestinal (19) and lung carcinoma (10). Furthermore, the loss of DPC4 has been demonstrated to enhance VEGF protein expression in human ovarian cancer cells (13). DPC4 expression is negatively associated with VEGF-C expression in colon cancer (33). The results of the aforementioned studies are all consistent with the results of the present study. Therefore, the loss of DPC4 may induce VEGF expression, increasing angiogenesis and consequently promoting the progression of cervical carcinoma. Although it is not yet clear how DPC4 modulates VEGF expression, DPC4 may be a candidate target for inhibiting cancer progression.

The association between DPC4 and TSP-1 was also investigated as TSP-1 is involved in angiogenesis, and may be a target gene of DPC4. The results demonstrated that the expression of DPC4 and TSP-1 was negatively associated, which suggested that the loss of DPC4 may induce the expression of TSP-1. Although reduced DPC4 expression and high TSP-1 expression are common in various cancer types (34-37), few studies have investigated the association between DPC4 and TSP-1 in tumorous tissue. Furthermore, contrary to the results of the present study, Schwarte-Waldhoff et al (4) indicated that DPC4 restoration may increase the expression of TSP-1 in human pancreatic adenocarcinoma cells. The correlation between DPC4 and TSP-1 in cervical carcinoma remains to be elucidated with further investigations required.
In conclusion, the loss of DPC4 and overexpression of VEGF may play important roles in the cervical carcinoma progression. The conceivable mechanism may involve the loss of DPC4, which induces angiogenesis by increasing VEGF expression, subsequently promoting the progression of cervical carcinoma. The results of the present study suggest that VEGF is a target gene regulated by DPC4. Furthermore, the negative expression of TSP-1 contributes to angiogenesis, and the correlation between DPC4 and TSP-1 requires further investigation.

\section{References}

1. Arbyn M, Castellsagué X, de Sanjosé S, Bruni L, Saraiya M, Bray $\mathrm{F}$ and Ferlay J: Worldwide burden of cervical cancer in 2008. Ann Oncol 22: 2675-2686, 2011.

2. Ferlay J, Shin HR, Bray F, Forman D, Mathers C and Parkin DM: GLOBOCAN 2008 v2.0, Cancer incidence and mortality worldwide: IARC CancerBase No. 10 [Internet]. International Agency for Research on Cancer, Lyon, 2010: 29, 2010. http://globocan. iarc.fr/Default.aspx. Accessed July 12, 2012.

3. Ferlay J, Shin HR, Bray F, Forman D, Mathers C and Parkin DM: Estimates of worldwide burden of cancer in 2008: GLOBOCAN 2008. Int J Cancer 127: 2893-2917, 2010.

4. Schwarte-Waldhoff I, Volpert OV, Bouck NP, Sipos B, Hahn SA, Klein-Scory S, Lüttges J, Klöppel G, Graeven U, Eilert-Micus C, et al: Smad4/DPC4-mediated tumor suppression through suppression of angiogenesis. Proc Natl Acad Sci USA 97: 9624-9629, 2000.

5. Zhao S, Venkatasubbarao K, Lazor JW, Sperry J, Jin C, Cao L and Freeman JW: Inhibition of STAT3 Tyr705 phosphorylation by Smad4 suppresses transforming growth factor beta-mediated invasion and metastasis in pancreatic cancer cells. Cancer Res 68: 4221-4228, 2008.

6. Lee S, Cho YS, Shim C, Kim J, Choi J, Oh S, Kim J, Zhang W and Lee J: Aberrant expression of Smad4 results in resistance against the growth-inhibitory effect of transforming growth factor-beta in the $\mathrm{SiHa}$ human cervical carcinoma cell line. Int J Cancer 94: 500-507, 2001.

7. Carmeliet P: Mechanisms of angiogenesis and arteriogenesis. Nat Med 6: 389-395, 2000.

8. Smith-McCune K, Zhu YH, Hanahan D and Arbeit J: Cross-species comparison of angiogenesis during the premalignant stages of squamous carcinogenesis in the human cervix and K14-HPV16 transgenic mice. Cancer Res 57: 1294-1300, 1997.

9. Veikkola T, Karkkainen M, Claesson-Welsh L and Alitalo K: Regulation of angiogenesis via vascular endothelial growth factor receptors. Cancer Res 60: 203-212, 2000.

10. Dai Y, Zhang X, Peng Y and Wang Z: The expression of cyclooxygenase-2, VEGF and PGs in CIN and cervical carcinoma. Gynecol Oncol 97: 96-103, 2005.

11. Kodama J, Hashimoto I, Seki N, Hongo A, Yoshinouchi M, Okuda $\mathrm{H}$ and Kudo T: Thrombospondin-1 and-2 Messenger RNA Expression in Invasive Cervical Cancer: Correlation with Angiogenesis and Prognosis. Clin Cancer Res 7: 2826-2831, 2001.

12. Ren B, Yee KO, Lawler J and Khosravi-Far R: Regulation of tumor angiogenesis by thrombospondin-1. Biochim Biophys Acta 1765: 178-188, 2006.

13. Chen C, Sun MZ, Liu S, Yeh D, Yu L, Song Y, Gong L, Hao L, $\mathrm{Hu} \mathrm{J}$ and Shao S: Smad4 mediates malignant behaviors of human ovarian carcinoma cell through the effect on expressions of E-cadherin, plasminogen activator inhibitor-1 and VEGF. BMB Rep 43: 554-560, 2010.

14. Lewin SN, Herzog TJ, Barrena Medel NI, Deutsch I, Burke WM, Sun X and Wright JD: Comparative performance of the 2009 international Federation of gynecology and obstetrics' staging system for uterine corpus cancer. Obstet Gynecol 116: 1141-1149, 2010.

15. Broders AC: Squamous cell epithelioma of the skin: A study of 256 cases. Ann Surg 73: 141-160, 1921.

16. Weidner N, Semple JP, Welch WR and Folkman J: Tumor angiogenesis and metastasis-correlation in invasive breast carcinoma. N Engl J Med 324: 1-8, 1991.

17. Baldus SE, Schwarz E, Lohrey C, Zapatka M, Landsberg S, Hahn SA, Schmidt D, Dienes HP, Schmiegel WH and Schwarte-Waldhoff I: Smad4 deficiency in cervical carcinoma cells. Oncogene 24: 810-819, 2005. 
18. Van Trappen PO, Steele D, Lowe DG, Baithun S, Beasley N, Thiele W, Weich H, Krishnan J, Shepherd JH, Pepper MS, et al: Expression of vascular endothelial growth factor (VEGF)-C and VEGF-D, and their receptor VEGFR-3, during different stages of cervical carcinogenesis. J Pathol 201: 544-554, 2003.

19. Miyaki M, Iijima T, Konishi M, Sakai K, Ishii A, Yasuno M, Hishima T, Koike M, Shitara N, Iwama T, et al: Higher frequency of Smad4 gene mutation in human colorectal cancer with distant metastasis. Oncogene 18: 3098-3103, 1999.

20. Kloth JN, Kenter GG, Spijker HS, Uljee S, Corver WE, Jordanova ES, Fleuren GJ and Gorter A: Expression of Smad2 and Smad4 in cervical cancer: Absent nuclear Smad4 expression correlates with poor survival. Mod Pathol 21: 866-875, 2008.

21. Hahn SA, Bartsch D, Schroers A, Galehdari H, Becker M Ramaswamy A, Schwarte-Waldhoff I, Maschek $\mathrm{H}$ and Schmiegel W: Mutations of the DPC4/Smad4 gene in biliary tract carcinoma. Cancer Res 58: 1124-1126, 1998.

22. Bartsch D, Hahn SA, Danichevski KD, Ramaswamy A, Bastian D, Galehdari H, Barth P, Schmiegel W, Simon B and Rothmund M: Mutations of the DPC4/Smad4 gene in neuroendocrine pancreatic tumors. Oncogene 18: 2367-2371, 1999.

23. Elliott RL and Blobe GC: Role of transforming growth factor Beta in human cancer. J Clin Oncol 23: 2078-2093, 2005.

24. Miyazono K, Suzuki H and Imamura T: Regulation of TGF-beta signaling and its roles in progression of tumors. Cancer Sci 94 230-234, 2003.

25. Schwarte-Waldhoff I and Schmiegel W: Smad4 transcriptional pathways and angiogenesis. Int J Gastrointest Cancer 31: 47-59, 2002.

26. Ke Z, Zhang X, Ma L and Wang L: Expression of DPC4/Smad4 in non-small-cell lung carcinoma and its relationship with angiogenesis. Neoplasma 55: 323-329, 2008.

27. Kim MH, Seo SS, Song YS, Kang DH, Park IA, Kang SB and Lee HP: Expression of cyclooxygenase-1 and-2 associated with expression of VEGF in primary cervical cancer and at metastatic lymph nodes. Gynecol Oncol 90: 83-90, 2003.

28. Hasturk S, Kemp B, Kalapurakal SK, Kurie JM, Hong WK and Lee JS: Expression of cyclooxygenase-1 and cyclooxygenase-2 in bronchial epithelium and nonsmall cell lung carcinoma. Cancer 94: 1023-1031, 2002.
29. Tokunaga T, Oshika Y, Abe Y, Ozeki Y, Sadahiro S, Kijima H, Tsuchida T, Yamazaki H, Ueyama Y, Tamaoki N and Nakamura M: Vascular endothelial growth factor (VEGF) mRNA isoform expression pattern is correlated with liver metastasis and poor prognosis in colon cancer. Br J Cancer 77: 998-1002, 1998.

30. Maeda K, Chung YS, Ogawa Y, Takatsuka S, Kang SM, Ogawa M, Sawada T and Sowa M: Prognostic value of vascular endothelial growth factor expression in gastric carcinoma. Cancer 77: 858-863, 1996.

31. Dameron KM, Volpert OV, Tainsky MA and Bouck N: Control of angiogenesis in fibroblasts by p53 regulation of thrombospondin-1. Science 265: 1582-1584, 1994.

32. Jin RJ, Kwak C, Lee SG, Lee CH, Soo CG, Park MS, Lee E and Lee SE: The application of an anti-angiogenic gene (thrombospondin-1) in the treatment of human prostate cancer xenografts. Cancer Gene Ther 7: 1537-1542, 2000.

33. Li X, Liu B, Xiao J, Yuan Y, Ma J and Zhang Y: Roles of VEGF-C and Smad4 in the lymphangiogenesis, lymphatic metastasis, and prognosis in colon cancer. J Gastrointest Surg 15: 2001-2010, 2011.

34. Alvarez AA, Axelrod JR, Whitaker RS, Isner PD, Bentley RC, Dodge RK and Rodriguez GC: Thrombospondin-1 expression in epithelial ovarian carcinoma: Association with p53 status, tumor angiogenesis, and survival in platinum-treated patients. Gynecol Oncol 82: 273-278, 2001.

35. Grossfeld GD, Ginsberg DA, Stein JP, Bochner BH, Esrig D, Groshen S, Dunn M, Nichols PW, Taylor CR, Skinner DG and Cote RJ: Thrombospondin-1 expression in bladder cancer: Association with p53 alterations, tumor angiogenesis, and tumor progression. J Natl Cancer Inst 89: 219-227, 1997.

36. Grant SW, Kyshtoobayeva AS, Kurosaki T, Jakowatz J and Fruehauf JP: Mutant p53 correlates with reduced expression of thrombospondin-1, increased angiogenesis, and metastatic progression in melanoma. Cancer Detect Prev 22: 185-194, 1998.

37. Tokunaga T, Nakamura M, Oshika Y, Tsuchida T, Kazuno M, Fukushima Y, Kawai K, Abe Y, Kijima H, Yamazaki H, et al: Alterations in tumour suppressor gene p53 correlate with inhibition of thrombospondin-1 gene expression in colon cancer cells. Virchows Arch 433: 415-418, 1998. 